\title{
EL BICAMERALISMO ITALIANO: ¿UUNA ANOMALÍA? (UNA RESPUESTA MUY BREVE) ${ }^{1}$ \\ The Italian bicameralism: An anomaly? (A very short answer)
}

\author{
ANTONIO IGNAZIO ARENA \\ Università degli Studi di Messina \\ antarena@unime.it
}

Cómo citar/Citation

Arena, A. I. (2020).

El bicameralismo italiano: 己̇una anomalía?

(Una respuesta muy breve).

Revista de Estudios Políticos, 190, 291-321.

doi: https://doi.org/10.18042/cepc/rep.190.10

\section{Resumen}

Se suele afirmar que el bicameralismo italiano es "anómalo». El escrito está dedicado a un examen crítico de esta tesis. En la primera parte nos centramos en los orígenes históricos del sistema parlamentario italiano, teniendo en cuenta las similitudes y diferencias con respecto a otras tradiciones constitucionales. Después se reflexiona sobre la composición del Senado (apoyando su reconducción al modelo de la Cámara de los sabios, y sobre la identidad de las funciones atribuidas a las dos Cámaras, y finalmente sobre la posibilidad de un trade-offentre la Segunda Cámara y los nuevos instrumentos de democracia directa y participativa.

\section{Palabras clave}

Bicameralismo italiano; bicameralismo; Senado; Cámara de los sabios; democracia directa y participativa.

1 El autor agradece sinceramente a Marta Manganaro su ayuda en la redacción en español de este escrito. 


\section{Abstract}

That Italian bicameralism is «anomalous» is a very widespread idea. This paper is dedicated to a critical exam of this thesis. In the first part, we focus on historical origins of Italian parliamentarism, comparing them with experiences of other Countries. Afterthat we analyze the composition of the Senato (that we see as a «House of sages») and the identical functions of the two Chambers. Finally, we argue on the possibility of a trade-off between the second chamber and the new instruments of direct and partecipative democracy.

\section{Keywords}

Italian bicameralism; bicameralism; Senate; House of sages; direct and participative democracy. 


\section{SUMARIO}

I. INTRODUCCIÓN. II. LA JUSTIFICACIÓN DEL SISTEMA PARLAMENTARIO ITALIANO (EL ORIGEN DEL PROBLEMA EN LA HISTORIA NO LINEAL DEL BICAMERALISMO). III. LA COMPOSICIÓN DEL PARLAMENTO ITALIANO. IV. FUNCIONES DEL PARLAMENTO, FORMA DE ESTADO Y SISTEMA POLÍTICO. V. ¿¿DEL BICAMERALISMO ANÓMALO AL BICAMERALISMO OBSOLETO? VI. CONCLUSIONES. BIBLIOGRAFIA.

\section{INTRODUCCIÓN}

Antes de los años noventa el sistema político italiano se consideraba «anómalo» en relación con las demás democracias occidentales, en gran parte (pero no solo) por el argumento de que no logró asegurar una alternancia genuina en el Gobierno durante un período de 50 años [...]. Sin embargo, si asumimos (como creemos que es seguro hacerlo) que la «norma» democrática es una genérica aceptación de ambas «reglas del juego» y de los medios por los cuales esas reglas pueden ser cambiadas (o propuestas para ser cambiadas), entonces está claro que la política italiana está muy lejos de esa norma — y que por lo tanto existe una especie de «anomalía» italiana-.

(Bull y Newell, 2009: 42-43).

Este pasaje expresa muy bien la visión que generalmente se tiene del sistema político italiano: si anteriormente se podría definir como «anómalo» porque incapaz de asegurar la alternancia entre diferentes fuerzas políticas en el Gobierno del país (llamada «democracia bloqueada»), ahora se puede considerar como tal porque está fraccionado por divisiones que, mucho más allá del conflicto natural entre partidos (característico del contexto democrático), se refieren a las normas constitucionales, a las «reglas del juego»y, en consecuencia, a los valores constitucionales estrechamente relacionados con ellas. Este conflicto se manifiesta en el intento de modificar la Constitución, que (ahora con cierta regularidad) se lleva a cabo por las mayorías del momento. En este sentido, se debatió correctamente sobre el «uso coyuntural de la Constitución» y el riesgo de transformar el conflicto político normal entre la mayoría y la oposición en un conflicto constitucional «monstruoso» ${ }^{2}$.

2 La expresión «uso coyuntural de la Constitución» proviene de Ruggeri (2006: 7 y ss..), que la usó en muchos escritos. 
Si hay un tema que siempre acompañó el debate sobre las reglas del juego en Italia, es la superación del bicameralismo paritario. También se considera principalmente como una anomalía, como un sistema que crea retrasos innecesarios, generalmente "criticised for slowing down the decision-making process» (Schmitt, 2014: 91). Podría suponerse que esta anomalía institucional terminó al variar el sistema político, y que este último, aunque a su vez muchos consideren "anómalo", siempre estuvo al menos... en posición de reconocerla.

¿Pero es el bicameralismo italiano realmente una anomalía? Y si es así, ¿por qué? La respuesta a estas preguntas es hoy quizá más importante que ayer debido a la transformación del sistema político y, más ampliamente, de la sociedad en Italia. De hecho, debemos reflexionar en primer lugar sobre este punto: los principales partidos políticos de la así llamada «democracia bloqueada» son los mismos que animan los trabajos de la Constituyente, que dio a luz al bicameralismo perfecto. Durante décadas, los partidos italianos mostraron con esta conformación del Parlamento una actitud crítica (si se desea, insatisfecha) pero, al mismo tiempo, responsable. Desde que el sistema político de la periodística pero incorrectamente llamada "primera república» se derrumba, la reforma de la segunda parte de la Constitución (que se discutió durante décadas) se percibe cada vez más como una prioridad: las críticas dirigidas a la Constitución crecen de manera exponencial y se extienden más allá de la disciplina del bicameralismo. Sin embargo, el corazón de estas críticas sigue siendo precisamente el papel del Parlamento, y especialmente del Senado.

Este trabajo no aborda el problema del presunto carácter (persistentemente) anómalo del sistema político italiano (la anomalía, en cualquier caso, no debería identificarse, en nuestra opinión, simplemente con el hecho de que las fuerzas políticas no están de acuerdo sobre posibles reformas constitucionales; residiría más bien en la distancia que existe entre muchas de estas propuestas de reforma y los valores constitucionales). En cambio, nos centramos en el sistema institucional y, por lo tanto, en la — real o supuestaanomalía institucional: el bicameralismo italiano y su raison d'être. Este es obviamente un tema muy complejo y en relación con el cual, como se sabe, las contribuciones ofrecidas por la doctrina son innumerables. Por tanto, no hay pretensión alguna aquí de tratar todo ello de manera exhaustiva. Las siguientes son simplemente breves consideraciones a este respecto.

En el siguiente párrafo trataremos de explicar el origen del problema relacionado con la justificación del bicameralismo en Italia y nos preguntaremos si, y en qué medida, es un problema común a otras historias y tradiciones constitucionales. Luego trataremos de ofrecer una explicación sobre la composición del Senado y, sobre esta base, comprender sus funciones. Finalmente, nos 
preguntaremos si existe relación —y de qué tipo- entre la crítica del bicameralismo paritario y la de la democracia representativa y si, en el contexto contemporáneo, se puede decir que la configuración del Senado es ya obsoleta.

\section{LA JUSTIFICACIÓN DEL SISTEMA PARLAMENTARIO ITALIANO (EL ORIGEN DEL PROBLEMA EN LA HISTORIA NO LINEAL DEL BICAMERALISMO)}

Muchos países en el mundo (más o menos la mitad ${ }^{3}$ ) tienen un sistema bicameral, pero el monocameralismo prevalece en los sistemas de la Unión Europea. Si la Cámara de los Lores no se cuenta, hay doce Estados miembros con una segunda cámara ${ }^{4}$.

Debido a los muchos elementos diferentes que puedan tomarse en consideración (Reynoso, 2009: 33), las clasificaciones del bicameralismo pueden ser las más variadas. Solemos distinguir entre bicameralismo perfecto (o simétrico) e imperfecto (o asimétrico). Esta distinción no se refiere a la composición de las dos cámaras, sino a las funciones asignadas a ellas. Cuando las dos cámaras tienen no solo las mismas funciones, sino también la misma composición, solo de manera incorrecta puede definirse el parlamento como bicameral. En tal hipótesis, es ciertamente más correcto calificarlo como monocameral.

El sistema parlamentario en el que solo se encuentran diferencias mínimas en la composición de las dos cámaras (a modo de ejemplo, solo en el número de miembros) también se puede clasificar como (de facto) monocameral. Este es el caso de Rumanía, donde, en cualquier caso, el Senatul debería ser abolido (en 2009 se celebró un referéndum consultivo a este respecto y el resultado fue en gran medida a favor de la abolición; sin embargo, al referéndum no siguió, en las formas establecidas, la necesaria revisión constitucional). Si el rumano es un Parlamento sustancialmente monocameral, el número de Estados miembros de la UE con un sistema bicameral se reduce a once. Entre estos últimos, Italia es la única que tiene un sistema bicameral perfecto: dos cámaras con composición diferente, pero funciones idénticas.

3 La incertidumbre depende de los criterios empleados en la doctrina. Por ejemplo, ¿hay que tomar en cuenta también las leyes de Estados no democráticos? En el caso de Estados contienente (como Estados Unidos, Canadá o India), ¿̨hay que analizar solo el nivel federal o también los niveles nacionales?

4 Bundesrat (Austria); Sénat/Senaat (Bélgica); Senát (República Checa), Sénat (Francia); Bundesrat (Alemania); Seanad Éireann (Irlanda); Senato (Italia); Eerste Kamer (Países Bajos), Senat (Polonia); Senatul (Rumanía), Državni Svet (Eslovenia y Senado (España). 
Según la importante tesis de Manzella, en cambio, el sistema italiano sería concebido como una forma peculiar de monocameralismo. En apoyo de esta conclusión se recuerda, entre otras cosas, cómo la Constitución democrática introdujo la noción unitaria de Parlamento, de la que no había rastro en el Estatuto Albertino (Manzella, 1977: 69). Debe señalarse que, debido a las diferencias existentes en la composición de las dos Cámaras, no se considera posible aceptar esta reconstrucción (que, de todas formas, sigue siendo una minoría).

Los orígenes de aquellos sistemas en los que la segunda cámara es (más que cualquier otra cosa) un órgano de enlace entre los diferentes niveles de gobierno del territorio son bastante peculiares. Así sucede, por ejemplo, en el caso del Bundesrat alemán, cuya configuración solo se puede entender tomando como referencia el específico "patrimonio constitucional» (Verfassungserbgut) de Alemania. En el análisis de la estructura (pero no de las competencias) de este órgano, los «elementos parlamentarios» permanecen subordinados a aquellos aspectos más directamente relacionados con las instancias federalistas y con las formas particulares de derivación de los ejecutivos «regionales» (Pezzini, 1990: 55 y ss.).

Como aquí nos interesa examinar el bicameralismo italiano y su carácter anómalo (verdadero o supuesto), no nos detendremos en los orígenes de este bicameralismo sui generis. El bicameralismo italiano (y el de muchos otros países) tiene muy poco que ver con eso. Además, todo sistema constitucional tiene su propia historia, por lo que no tenemos una sola explicación del origen del bicameralismo.

En muchos Estados europeos (por razones históricas obvias, a diferencia de lo que sucedió en Estados Unidos), el bicameralismo se desarrolla como una institución estrictamente dependiente de la forma aristocrática del Estado. El Parlamento está compuesto únicamente por los miembros de las clases privilegiadas, cuyos miembros son finalmente seleccionados sobre la base del censo. En Inglaterra, y más tarde en Italia, debe mantenerse firme una distinción entre la antigua nobleza y la nueva élite burguesa. Durante el siglo XIX, e incluso a principios del siglo $\mathrm{xx}$, los sistemas bicamerales de estos países reflejan esta distinción, típica de la mentalidad aristocrática.

Algo similar también se encuentra en Francia — piénsense en las Constituciones de 1814 y 1830 (Ellul, 2014: 378)—, así como en España (en particular, recuérdense la Constitución de 1834$)^{5}$, pero durante el siglo xIx los

5 Vid. Castellà Andreu (2018a: 48), que escribe: «Todas las constituciones, salvo la Constitución de Cádiz de 1812 y la republicana de 1931, incorporen una segunda Cámera. El Senado desempeña una función conservadora y moderadora del Congreso de los Diputados en todas las constituciones desde les de 1834 y 1837. Con variadas formas de composición y elección, predomina el carácter aristocrático sobre el democrático [...] Solo el proyecto constitucional de la I República (1873) optó por 
sistemas parlamentarios de estos Estados cambiaron muchas veces y radicalmente. Solo con referencia a la Constitución española de 1869, se puede decir que el Senado asume, gracias a la influencia de la Constitución de Estados Unidos, «el papel de representar intereses territoriales y locales», pero esta Constitución tuvo una vida muy corta (Seijas Villadangos, 20I6: 59).

En Italia y en Inglaterra la separación del legislativo en dos ramas se considera incluso indispensable (Paladin, 1990: 1). La Cámara Baja es electiva, con sufragio restringido basado en el censo. Es la Cámara de la burguesía. La Cámara Alta no lo es. Por esta razón, Bagehot cree que este último representa un «ídolo distinto del dinero» (Bagehot, 1995: 113). La herencia (Inglaterra) y el nombramiento del rey (Italia) son los criterios generalmente utilizados para la formación de la Cámara Alta.

Esta justificación del bicameralismo entra en crisis a principios del siglo XX. Así, en Inglaterra hay una primera disminución de los poderes de la Cámara de los Comunes con las Parliament Acts de 1911 y 1949. Las reformas deberían haber abierto el camino para una transformación radical de su modo de formación, sobre unas bases populares, pero esto todavía no se ha verificado: «Se dijo que la legislación promulgada en 1911 que limitaba los poderes legales de los lores, en su preámbulo, era una medida temporal en espera de la "sustitución de la Cámara de los Lores tal como existe actualmente [con] una segunda Cámara constituida en lugar de una popular de base hereditaria”. Tal desarrollo aún se espera» (Elliott y Thomas, 2017: 191).

Solo con el House of Lords Act de 1999 se puso fin a muchos escaños pertenecientes a los hereditary peers: hoy en día, la mayoría son nominados por la reina, con el patronage del prime minister (según lo establece el Life Peerages Act de 1958). Este poder de propuesta a menudo fue criticado y se discute si se puede decir que la composición actual de la Cámara de los Lores sea coherente con un sistema democrático. En la esfera pública, la institución a menudo se llama "House of cronies», ya que el Gobierno puede manipular su composición, ofreciendo peerages («dignidad de los lores») a cambio de la lealtad política y de favores; los pocos lores hereditarios son llamados tulips (temporary unpaid lords in parliament) (Caravale, 2000: 553).

Sin embargo, la House of Lords también fue vista como un modelo: una Cámara "characterised as embodying a particular measure of wisdom, balance and expertise» (Gélard, 2006: 11). En Italia no hubo una transición lenta de la aristocracia a la democracia. El Senato del Regno está fascistizado por los nuevos

un Senado de representación de los «Estados que integran la nación española», siguiendo de cerca, en cuanto a su composición y elección, el modelo federal norteamericano entonces vigente». 
nombramientos (la Camera dei deputati deja de controlar el Gobierno y se transforma en 1939 en la Camera dei fasci e delle corporazioni). Durante la era autocrática, la función de las dos Cámaras es la de "colaborar con el Gobierno» (así, también formalmente, en la Ley 129 de 1939) (Melis, 1990: 269).

Después de la Segunda Guerra Mundial, con el cambio democrático, la Asamblea Constituyente tuvo que hacer frente al problema del nuevo Parlamento. En Italia, como en otras partes, la distinción entre cámara alta y cámara baja se volvió anacrónica. Si por inercia el lenguaje cambia muy lentamente y se siguen utilizando ciertas expresiones, en la perspectiva democrática no tiene sentido hablar de cámaras altas o bajas.

El problema de la justificación del bicameralismo en Italia, como en otros países, se debe, por lo tanto, al ocaso de la aristocracia como una forma de Estado (no por casualidad, hoy en día los Estados europeos más cercanos a Italia, por coherencia democrática y la estructura cultural y económica, tienen dos cámaras y, casi en todos, la justificación del bicameralismo presenta ciertos problemas).

\section{LA COMPOSICIÓN DEL PARLAMENTO ITALIANO}

Hemos tratado de mostrar — aunque en síntesis extrema — que la historia del bicameralismo es todo menos lineal. Cada país tiene sus especificidades, aunque no faltan puntos de contacto entre las diferentes historias constitucionales de Europa. En Italia, el problema de la justificación del bicameralismo está estrechamente relacionado con el nacimiento de la democracia.

Los únicos elementos que hoy distinguen a la Cámara y al Senado son, como se sabe: el número de miembros (fijo, después de la reforma constitucional de 1963); la edad mínima requerida para elegir y ser elegido, y la presencia de una componente no electiva en una de las dos Cámaras.

Además debe añadirse que el Senado, de conformidad con el art. 57 de la Constitución italiana, es elegido a nivel regional, pero esto - aunque produzca algunas consecuencias no insignificantes en la disciplina electoralno la convierte en una "Cámara de las regiones» ${ }^{6}$.

En resumen, los senadores electos son exactamente la mitad de los diputados (por tanto, la proporción entre el número de representantes electos y el

6 Las palabras «es elegido a nivel regional», aunque conjuntamente a la previsión relativa al número mínimo de senadores por cada región, no pueden ser entendidas en el sentido que en el Senado estén representantes de las mismas regiones (no se prevé, de hecho, alguna vinculación entre la composición del Senado y las instituciones regionales). 
de votantes es mayor para los senadores). Cabe señalar que esto debería mantenerse incluso si la propuesta de revisión constitucional sobre la cual el cuerpo electoral será llamado a pronunciarse próximamente se aprobara (se propone reducir el número de los parlamentarios: de 630 a 400 diputados, de 315 senadores electos a 200).

La edad mínima requerida para elegir a los senadores es de veinticinco años, en lugar de los dieciocho para la Cámara. El derecho al electorado pasivo se adquiere para el Senado solo a la edad de cuarenta ańos, es decir, quince años más tarde que para la Cámara. Esto corresponde a la misma etimología de la palabra Senado; está conectado a uno de los modelos de segunda cámara compatibles con la democracia: la Cámara de los sabios.

El factor edad se examinó principalmente en términos electorales. Se planteó en particular si el número diferente de los que tienen derecho puede determinar una conformación política diferente del Senado con respecto a la Cámara. La respuesta parece ser negativa. En el curso de la historia republicana, la diferencia con respecto a la edad mínima requerida para ejercer el derecho de voto no ha tenido un impacto significativo en los resultados de las elecciones y, por lo tanto, en la relación de confianza entre el Parlamento y el Gobierno. Todo ello llevó a juzgar las diferentes edades mínimas requeridas como sustancialmente irrelevantes.

Durante su discurso el 8 de mayo de 1948, con motivo de su inauguración, el presidente del Senado Bonomi, por otro lado, indicó de esta manera la especificidad del Senado: no un papel de controlador ni de freno sobre el ímpetu y la audacia de la Cámara, pero de cuidadoso estudio y propuesta por parte de hombres con mayor experiencia ${ }^{7}$.

Para evitar dudas, se debe de aclarar de inmediato que el vínculo entre la edad y la sabiduría no debe ser mitificado. Quién escribe no tiene intención de proceder en esta dirección. Sin embargo, se debe señalar que requerir más experiencia para elegir y, sobre todo, ser elegido, es una forma profundamente igualitaria de diversificar las dos ramas de un parlamento. En otras palabras, la edad es un criterio extremadamente igualitario para justificar la restricción del electorado (activo y pasivo). Sin embargo, se debe señalar de ahora en adelante que, por extraño que parezca, este aspecto a menudo se ha pasado por alto ${ }^{8}$.

7 «Discorso d'insediamento del Presidente Ivanoe Bonomi» (8 Maggio 1948-20 Aprile 1951), Senato della Repubblica, 8 Maggio 1948, I legislatura.

8 Hay que subrayar que el sistema político, en los últimos años, fue particularmente critico con la edad mínima requerida para elegir los senadores y ser elegidos para el Senado. Durante la XVIII legislatura se presentaron muchos proyectos de ley (firmados por parlamentarios tanto de la mayoría como de la oposición) para eliminar las 
Ya que se argumenta que es un criterio igualitario, más bien muy igualitario, debemos tratar de aclararlo de inmediato. La comparación puede ayudar. Cabe señalar que, a diferencia de lo que ocurre para la House of Lords o para el Seanad irlandés, el criterio selectivo no es el mérito o la competencia (el éxito conseguido en el propio sector laboral, titulación académica, etc. $)^{9}$, sino la experiencia de vida (junto con la elección, no con el nombramiento).

Podría objetarse que el mérito es también un criterio extremadamente igualitario. Esta tesis podría ser sostenida al identificar el mérito con el éxito económico. Pero se trata de una argumentación muy frágil, en primer lugar porque - como afirma el propio Hayek - en una sociedad libre no es aceptable la identificación entre éxito y mérito ${ }^{10}$. En segundo lugar, porque -al menos de acuerdo con la lógica interna del constitucionalismo democráticoel mercado sobre el que no se interviene no es realmente libre; para que lo sea, es necesaria la intervención del poder público en la esfera económica y esto solo puede, con dificultad, acercar la esfera económica al ideal de la

diferencias en este aspecto entre la Cámara de los Diputados y el Senado, o para reducir las edades mínimas requeridas: cfr. AS 1116 (firmado por el On. Calderoli, Lega) y AC 1511-1647-1826-1873-A (firmado por los parlamentarios PD y M5S), ambos para eliminar la previsión relativa a la edad mínima de veinticinco años para elegir a los senadores (en la AC 1647, bajo firma del On. Ceccanti, PD, se reducía también la edad mínima para el ejercicio del derecho de electorado pasivo, de cuarenta a veinticinco ańos; lo mismo en AC 1873, bajo la firma de la On. Meloni, Fd'I-AN). Actualmente estas propuestas se han incluido en un único proyecto (AC 1511), aprobado en primera lectura por la Cámara, el cual prevé solo la supresión de la edad mínima de veinticinco años requerida para la elección de los senadores. Por otra parte, no faltan críticas en relación con la edad mínima requerida para el derecho de electorado activo (Lupo, 2019: 71 y ss.).

9 La presencia de "graduate representatives» se ve favorecida por una gran parte de la doctrina irlandesa (v. Doherty, 1996: 16).

10 Según Hayek (2011: 197 y ss.): «A pesar de que muchos la consideran perfectamente natural, la afirmación según la cual nadie debería ser retribuido más de lo que le toque por su esfuerzo y trabajo se basa sobre una presunción colosal. Presume la capacidad de juzgar en cada caso individual cómo las personas hayan sabido aprovechar de las diferentes oportunidades y talentos a su disposición y cuanto meritorios son sus logros a la luz de todas las circunstancias que los hicieron posibles. Presume de que algunos hombres sean capaces de decidir en modo concluyente cuanto valga una persona y tengan el derecho de decidir lo que una persona pueda realizar. Presume entonces de lo que la argumentación a favor de la liberta expresamente rechaza: que podemos saber y sabemos todo lo que guía la acción de un particular. Una sociedad en la que un particular pudiera estar en la posición correspondiente a las ideas humanas del mérito moral sería por lo tanto exactamente lo opuesto de una sociedad libre». 
competencia perfecta. Si el «mérito constitucional» parece poderse «reconocer al paradigma representado por el mercado de la competencia perfecta, que no solo se presenta en general como un sistema eficiente de asignación de recursos, sino que también (y sobre todo) combina virtuosamente la libertad y la igualdad de los sujetos actuantes en la esfera económica tanto en el lado de la oferta como en el de la demanda» (D'Andrea, 2018: 1004), no se puede decir lo mismo para una esfera económica — como la de hoy — atravesada por desigualdades demasiado profundas y en la que el mecanismo de la libre competencia está distorsionado (sobre todo por la presencia de oligopolios y monopolios) ${ }^{11}$. Además, aceptar la idea de que el éxito en los negocios es una medida del valor de una persona y que, por lo tanto, sobre la base de este éxito es legítimo que tenga una ventaja en la competencia electoral o, es más, configurar a partir de esta idea las instituciones (y en particular el sistema bicameral), es inaceptable en la perspectiva democrática porque se coloca en contraste con el principio de igualdad (que impone el reconocimiento de igual dignidad a las opiniones políticas de cada uno, independientemente de sus condiciones económicas y sociales).

Lo mismo vale para cualquier otro tipo de éxito, de cualquier manera que se quiera identificar. El éxito en la esfera cultural o, más simplemente, la competencia relacionada con la posesión de un título o la aprobación de ciertos exámenes no es un criterio sobre el cual se puede restringir el derecho de sufragio activo o pasivo, incluso con respecto a una de las dos Cámaras. Esta es también una idea aristocrática. En Italia, a pesar de haber contado el apoyo de algunas personas durante el trabajo de la Asamblea Constituyente, se descartó con una gran mayoría ${ }^{12}$. Hoy parece haber vuelto a estar de moda ${ }^{13}$,

11 Se refiere especialmente a aquellos «poderes enormes, incontrolados, irresponsables, no estructurados democráticamente de las empresas colosales» sobre los cuales es fundamental la reflexión crítica de Predieri (1963: 242).

12 Bastante singular, como se señaló en otra parte, la posición (luego severamente criticada) expresada por el On. Bulloni, según la cual «no hay perjuicio para los principios de la democracia, si se reconoce, por ejemplo, al profesor universitario el derecho a una pluralidad de votos [...]. A quien consume toda su existencia y sus recursos de su genio en el estudio debe ser reconocido un puesto que lo diferencia, por ejemplo, del conserje de la propia universidad».

13 Véase Brennan (2018: 208, 211), según el cual «en las democracias, los más altos poseedores del poder son los votantes. Si estos son sistemáticamente incompetentes, como entidad colectiva, las consecuencias pueden ser trágicas. No hay necesidad de subestimar el daño que puede venir de la votación. El voto puede ser, y ha sido, desastroso [...]. El principio de competencia requiere que cada decisión sea tomada de manera competente y razonable por personas competentes y razonables. Se aplica no 
pero hay que recordar que la aristocracia puede adoptar diferentes formas: es necesario temer, desde una perspectiva democrática, no solo la plutocracia, sino también la tecnocracia. Difícilmente sería posible objetar que en muchos sistemas democráticos la competencia es el criterio por el cual (en gran medida) los empleados de la Administración o los miembros del poder judicial son seleccionados. Esto sucede porque estos órganos están llamados a ser imparciales: en ellos, el sistema político no se mezcla (y es fundamental que no se mezcle) para garantizar el equilibrio entre poderes. El Parlamento es, en cambio, el órgano político por excelencia. De hecho, incluso cuando la Cámara de los sabios se concibe como una cámara de las excelencias, no se accede por oposición, sino por elección por sufragio restringido o por nombramiento. Y no es casualidad que en Italia el criterio del censo esté asociado con la elección y que el espacio reservado para los nombramientos presidenciales sea, en cambio, reducido.

En este sentido, de manera más general, observamos que el número de senadores no electivos, incluidos los expresidentes de la República, es pequeño. El jefe de Estado puede designar hasta un máximo de cinco senadores vitalicios, ciudadanos italianos que hayan honrado a su patria por méritos muy altos en el campo social, científico, artístico o literario. Cabe señalar que el decreto de nombramiento es un acto no solo formal, sino también sustancialmente presidencial. El Gobierno, en otras palabras, no decide.

La extensión de la prerrogativa del jefe de Estado es dudosa. Solo dos presidentes (Pertini y Cossiga) consideraron que podrían nombrar a cinco senadores vitalicios, independientemente del número de senadores de nombramiento presidencial ya presentes en el Senado. Todos los otros presidentes interpretaron el art. 59 de la Constitución italiana en el sentido de que el número total de senadores designados no puede exceder el límite máximo de cinco. Esto es para evitar, totalmente de acuerdo con lo que se dice aquí, que a través del nombramiento las relaciones de poder entre los grupos parlamentarios, según lo que determinen las elecciones, puedan ser alteradas ${ }^{14}$. Después de todo, incluso el análisis de los senadores no electivos está en línea con el modelo de la Cámara de los sabios. Sin embargo, la democracia se basa en el reconocimiento de la igualdad (de opiniones) de todos los miembros de la comunidad política. Por tanto, el

solo a las decisiones de un jurado, sino también a cualquier decisión importante tomada por aquellos que tienen el poder político».

14 En la propuesta de ley de reforma constitucional sobre la que el cuerpo electoral será llamado a pronunciarse se establece claramente que el número de senadores de nombramiento presidencial no puede ser más de cinco. 
número de senadores no electivos se reduce. También los senadores deben ser elegidos generalmente por el pueblo ${ }^{15}$.

En la Constitución se armoniza esta idea clave de democracia (la igual dignidad de todos los miembros de la comunidad política) con el mantenimiento de una Cámara de los sabios ${ }^{16}$. Desde un cierto punto de vista, de hecho, podemos encontrar una continuidad entre el Senato del Regno y el Senado de la República. Y esta continuidad explica el mantenimiento (parcial) del nombre, Senado. La sabiduría solo se ha relacionado con la edad: esta es la razón por la que una de las dos Cámaras está compuesta enteramente por personas que han alcanzado al menos cuarenta ańos de edad. Cabe recordar que una consideración similar del factor de la edad se encuentra en el título II de la parte II de la Constitución italiana: entre los requisitos para ocupar el cargo de presidente de la República, de hecho, está la edad mínima de cincuenta ańos.

Es raro que la composición del Senado se explique en estos términos - la edad mínima requerida para los senadores es, merece la pena repetir, generalmente considerada insuficiente para distinguir las dos Cámaras (Salerno, 1998: 26)—. Las tres explicaciones que siguen son mucho más frecuentes: a) dos ojos son mejores que uno; b) teoría de la incompletitud, y c) doctrina del mero compromiso histórico.

Según muchos, las diferencias entre las dos Cámaras son completamente insignificantes. Mucho más importante es detenerse en la identidad de las funciones que se les atribuyen. De hecho, el bicameralismo permite que una Cámara corrija los errores o los descuidos de la otra. Incluso en países distintos de Italia, esta explicación es bastante común: «Al modo

15 Según parte de la doctrina (Pace, 2016: 8), la Constitución italiana (ex art. 1) exige la elección directa de las asambleas legislativas.

16 Obviamente no nos interesa sostener que este sea el original intent de los padres constituyentes — para una síntesis de las voluntades políticas y, por lo tanto, de los argumentos utilizados en la Asamblea constituyente, véae, entre muchos, Cecchetti (2018: 1599—; además, la doctrina del original intent es hoy en general criticada por los mismos defensores del originalismo, para quienes se trata más bien de identificar el original meaning, es decir, el significado más acorde con la letra de la Constitución (Scalia, 2018: 37 y ss.). Nos parece que la interpretación propuesta en el texto es la que mejor responde a las disposiciones que la Constitución dedica al Parlamento y, aunque aquí se destacan algunos aspectos que a veces se han pasado por alto en silencio, también nos parece que no está en conflicto con la Constitución viviente. Sucede, de hecho, que en la interpretación de las prácticas sociales (y, por lo tanto, también de la ley), algunos aspectos, precisamente porque están ampliamente compartidos, generalmente pueden callarse o destacar de manera poco relevante. 
como la dualidad de ojos o de oídos no perjudica a la visión ni a la audición, sino que presta relieve a las percepciones de ambos sentidos, así también el bicameralismo permite una apreciación más completa y acertada de las realidades nacionales»: Pérez Serrano, 1976: 741). En consecuencia (se argumenta), el bicameralismo en general, y el italiano en particular, debería mejorar la calidad de la legislación.

Esta tesis no parece ser aceptable. Primero, no tenemos ninguna razón para asignar a la organización una importancia secundaria con respecto a las funciones. Debe recordarse que entre la organización y las funciones hay una conexión muy estrecha, una relación circular de condicionamiento recíproco. Las diferencias en la organización son tan importantes como la identidad de las funciones. En segundo lugar, el sistema bicameral, ya sea simétrico o no, no es (como tal) garantía de legislación de mejor calidad (Lippolis, 2012: 32). El bicameralismo no tiene una superioridad ontológica en comparación con el monocameralismo. Los Parlamentos monocamerales no son más propensos que los Parlamentos bicamerales a violar los derechos o «comportarse de manera caprichosa»: "Are not more liable to violate rights or to behave capriciously» (Przeworski, 2010: 142).

También se ha escrito que el Senado es un órgano con una estructura incompleta; por tanto, debería transformarse en una cámara de las regiones (o autonomías locales). Este tema se ha utilizado ampliamente durante el debate político (y académico) que precedió al referéndum constitucional de 2016. Sin lugar a dudas, muchos diputados de la Asamblea Constituyente (de los demócratas cristianos u otras fuerzas políticas moderadas) estaban a favor de un sistema bicameral imperfecto y hubieran querido un Senado de las regiones (y, al menos, algunos, representante al mismo tiempo del mundo de la economía y del trabajo). Creían que el pacto entre los territorios, no solo entre los partidos, tendría que fortalecerse a través de una segunda Cámara con un sistema de representación profundamente modificado y con una distribución diferente de poderes entre las dos ramas del Parlamento (Ceccanti, 2015: 207).

Mortati advirtió que ni el Senado ni las regiones (una vez constituidas: las regiones ordinarias se constituyeron solo en 1970) hubieran funcionado adecuadamente sin llevar los intereses regionales «al centro", es decir, dentro del sistema institucional a nivel nacional. Sin embargo, cabe señalar que, al mismo tiempo, Mortati se opuso absolutamente a un Senado débil, en una posición de inferioridad con respecto a la Cámara de los Diputados:

De hecho, no se debe de olvidar que cuando se habla de bicameralismo se está apuntando a la formación de asambleas que tengan una plena paridad de posición entre ellas no solo respecto a la formación de las leyes, sino al gobierno [...]. Una asamblea que estuviera institucionalmente en una posición de 
inferioridad no sería una cámara, sino algo sustancialmente diferente y entonces ajeno a la esfera de los problemas aquí considerados (Mortati, 1946: 433).

Que el reconocimiento del pluralismo territorial requiera una cámara de las regiones es una idea ampliamente compartida, y no solo entre los estudiosos italianos - por ejemplo, adquiere gran importancia en el contexto de las discusiones críticas relacionadas con el Senado español, debido a su "carácter híbrido" (Fernandez Segado, 1982: 80). Hay que decir muy claramente, sin embargo, que esta idea no fue aceptada por la Asamblea Constituyente italiana. Como se sabe, esto ocurrió debido a la oposición de las fuerzas políticas socialistas. Estas últimas estaban a favor de un Parlamento de cámara única («uno è il popolo, una è la Camera che lo rappresenta», podría decirse para resumir su punto de vista).

En el texto de la Constitución italiana solo quedan algunos rastros de la propuesta de una cámara de las regiones (la referencia es al art. 57, párrafo I, antes mencionado), así como de la idea de una Cámara que represente a las categorías profesionales (ver art. 99) ${ }^{17}$. No obstante, quizás también porque se cree que el de la cámara de las autonomías es un modelo de éxito a la luz de la experiencia de otros países, siempre se discutió la transformación necesaria del Senado en una cámara de las regiones - cuando se dice que es un modelo de éxito, se piensa principalmente en el Senado de Estados Unidos o en el Bundesrat alemán-.

Sin embargo, raramente se recuerda que, en lo que respecta al primero, lo que lo caracteriza como una cámara de autonomía (si es así como se entiende) es el hecho de que todos los Estados tienen el mismo número de senadores, independientemente de su consistencia demográfica. Nadie (salvo error) propone algo similar para el Senado italiano ${ }^{18}$.

En cuanto al segundo, ya vimos cómo es el producto de una historia completamente peculiar. Desde el punto de vista estructural, es más un órgano de enlace. De hecho, quienes lo consideran un modelo, también pueden imaginar la abolición pura y simple del Senado y la constitucionalización de una Conferencia de Estado-regiones, pero con una expansión significativa de las competencias de esta última (Ruggeri, 2015: 249; contra véase, para todos, De

17 Hoy en día raramente se sigue este modelo. Un ejemplo, entre los países europeos, es el Consejo nacional esloveno.

18 Además, según parte de la doctrina, (véase para todos, Chessa, 2013: 668), aunque a todas las regiones italianas se atribuyera un igual número de senadores, el Senado no se convertiría solo por eso en una Cámara de las autonomías. 
Fiores, 2007: 544) ${ }^{19}$. En cambio, es difícil decir que otras cámaras de las autonomías (Francia, España, Austria) hayan tenido éxito. Sin embargo, que el Senado italiano se transforme en una cámara de las regiones es una propuesta política, no la interpretación de la Constitución actual. El bicameralismo no debe explicarse a partir de lo que podría ser o podría haber sido (o de lo que a todos les gustaría que fuera), sino de lo que, según las normas constitucionales actuales, está llamado a ser. Por esta razón, incluso la teoría de la incompletitud parece que deba ser rechazada.

Finalmente, algunos académicos no ven en la composición de las dos Cámaras ninguna opción correspondiente a un modelo. Piensan más bien que el sistema bicameral italiano es anómalo en comparación con cualquier prototipo concebible. Por lo tanto, por razones como esta, es ciertamente preferible admitir que la composición del Parlamento italiano refleja solo contingencias especiales y acuerdos políticos, sin buscar más justificaciones (ex multis, véase Ferrara, 1984: 6; Di Ciolo, 1989: 1168).

Ciertamente, no se puede negar que la configuración del bicameralismo italiano es el resultado de un compromiso (toda la Constitución es fruto de un compromiso noble, no solo ideológico, sino garantista). Sin embargo, el juicio por el cual sería anormal con respecto a cualquier modelo es, en nuestra opinión, demasiado severo. El Senado debería ser, por Constitución, una cámara de sabios, formada por hombres con mayor experiencia.

Podría objetarse que el Senado no es realmente una cámara de sabios. Por ejemplo, la conexión entre la sabiduría y la edad podría ser desafiada. Sin embargo, si esta no es una idea política simple, un juicio puro y subjetivo (tal vez formulado pensando también en el comportamiento no ejemplar de este o aquel senador), entonces de ello deriva que las normas que establecen una edad mínima para ocupar un cargo público (incluida la elección del presidente de la República) o para la adquisición de la capacidad de actuar (para tomar otro ejemplo) son elecciones arbitrarias del constituyente o del legislador, sin más justificaciones.

Todo puede explicarse, por supuesto, y necesitamos ver qué entendemos por «más justificaciones». Si, por ejemplo, nos preguntamos por qué la edad mínima requerida para ser electo al Senado es de cuarenta años, en lugar de los

19 Otra posibilidad, hoy muy discutida, es aquella de dar actuación al art. 11 de la Ley Constitucional 3 del 2001, relativa a la comisión bicameral para las cuestiones regionales en composición integrada, pero asegurando "conexiones entre la sede de colaboración intergubernamental y aquella parlamentaria de manera que el sistema de las autonomías se manifiesta con una única voluntad» (Pajno, 2018: 255). Sobre estos temas, véase también Bin y Ruggiu (2006: part. 918). 
cuarenta y uno, debe admitirse que no hay mucho más que decir que «así se decidió» (tal vez por el encanto de las cifras redondas). Con respecto a esta pregunta, no hay espacio para una justificación adicional. No obstante, si nos preguntamos por qué a un niño de doce años no se le permite conducir un vehículo o a uno de veinticinco años convertirse en jefe de Estado, el asunto cambia. Parece que en todos los casos en los que el sistema legal requiere edades mínimas subyace la idea de que para poder mantener ciertos comportamientos es necesario tener cierta experiencia. Esta idea tiene raíces profundas en nuestra cultura (y quizás incluso en una base, por así decirlo, precultural). Solo en el caso en que fuese refutada, podríamos aceptar la tesis para la cual el Senado italiano es simplemente el resultado de un compromiso y no es atribuible a ningún modelo de segunda cámara.

\section{FUNCIONES DEL PARLAMENTO, FORMA DE ESTADO Y SISTEMA POLÍTICO}

El bicameralismo italiano se considera anómalo, especialmente porque las dos Cámaras tienen los mismos poderes. Esto puede explicarse de varias maneras.

Según la conocida tesis de Wheare, prever un sistema bicameral perfecto en el marco de una forma parlamentaria de gobierno significa, en resumen, «looking for trouble» (Wheare, 1963: 200), sobre todo porque esto corre el riesgo de debilitar excesivamente al Gobierno. Por tanto, un Senado con los mismos poderes que la Cámara resta fuerza a la forma de gobierno parlamentaria porque supone un factor de debilidad.

$\mathrm{Si}$, en cambio, seguimos la famosa clasificación propuesta por Lijphart, la presencia de dos Cámaras que (debido a su composición) generalmente tienen el mismo color político y los mismos poderes es simplemente superflua (Lijphart, 1984: 113). En esta perspectiva, el Senado italiano es anómalo, no tanto porque debilita al Gobierno, sino porque es una duplicación inútil de la Cámara.

Ackerman, de otra manera, ha argumentado que «the symmetry in the electoral system eliminates the legitimacy tie threatened by fully symmetrical bicamerality» (Ackerman, 2000: 684). En otras palabras, y de acuerdo con este enfoque, dado que el sistema electoral de las dos ramas es el mismo (aunque con alguna diferenciación), desaparecen las razones que sustentan el bicameralismo ${ }^{20}$.

20 Parte de la doctrina italiana considera que las diferencias en el sistema electoral y en los reglamentos parlamentarios de las dos ramas del Parlamento deberían ser reducidas 
A estos argumentos se agrega la importancia por la cual entre las democracias europeas la italiana es la única con un sistema de este tipo. Incluso en la Italia monárquica, el bicameralismo no era perfecto. En particular, el Senato del Regno no podía aprobar una moción de desconfianza en el Gobierno. En el contexto contemporáneo, el Senado italiano no es el único que controla el Gobierno. El Senado holandés también es competente en tal sentido, pero no tiene las mismas facultades que la Cámara; sin embargo, no se concibe como segunda, sino como primera cámara, Eerste Kamer. Sin embargo, en Italia no se puede decir cuál de las dos Cámaras es la segunda).

Las cuatro críticas merecen la mayor de las consideraciones, incluso si inducen a descuidar dos cuestiones igualmente importantes: primero, la anomalía italiana parece estar relacionada solo con la forma parlamentaria de gobierno; segundo, deriva directamente de la composición de las dos Cámaras.

En particular, la crítica de Wheare al bicameralismo perfecto está comprensiblemente limitada a la forma parlamentaria de gobierno. En países como Estados Unidos o Suiza, las dos Cámaras tienen notoriamente los mismos poderes (o casi) en el proceso legislativo ${ }^{21}$. Esto en sí mismo no se considera un problema. Se ha argumentado que si las dos ramas tienen los mismos poderes en el procedimiento legislativo, el tiempo requerido para la aprobación de una ley se prolonga sin razón (Cheli, 1987: 324). Esta crítica también debería aplicarse a los países que adoptan un sistema bicameral perfecto, pero no una forma parlamentaria de gobierno. En realidad, el procedimiento legislativo puede concluirse, incluso en Italia, muy rápidamente, si solo existiera el consenso necesario a tal respecto. $\mathrm{Y}$, francamente, no se entiende por qué en una democracia el proceso de creación de la ley debe completarse rápidamente, salvo en el caso de que esta sea la orientación del Parlamento.

Es cierto que la presencia de dos cámaras igualmente involucradas en los procedimientos fiduciarios puede conllevar mayores dificultades para el

al mínimo para asegurar el buen funcionamiento del Parlamento (Ibrido, 2017: 17 y ss.; Lupo, 2018: 4 y ss.).

21 Como se sabe, en virtud del art. 1, sec. 7, par. 1, de la Constitución de Estados Unidos, «all bills for raising Revenue shall originate in the House of Representatives; but the Senate may propose or concur with Amendments as on other Bills». En Italia, el art. 70 de la Constitución, según el cual las leyes se aprueban en el mismo texto por parte de ambas Cámaras, se interpreta rígidamente por parte de la Corte Costituzionale (sent. n. 292 del 1984). Según la Corte, el carácter perfecto del bicameralismo italiano excluye que una Cámara pueda aportar modificaciones una vez que se haya aprobado definitivamente, modificaciones que se configurarían como «enmiendas subrepticias» y que generan dudas sobre la «intención del legislador». 
Gobierno; en realidad, las críticas de Lijphart y Ackerman presuponen que la identidad en la composición política de las dos Cámaras sea el verdadero problema. Entonces, si las dos Cámaras no tienen el mismo color político, esto termina debilitando la acción del Gobierno; si, en cambio, tienen el mismo color político, una de las dos sobra y no sirve para limitar aún más los poderes del Gobierno.

Sin embargo, ninguno de estos autores (salvo errores) cree que el bicameralismo en sí mismo no sea razonable, ni tampoco el hecho de prever una segunda rama que responda al modelo de la Cámara de los sabios. Las interesantes críticas al sistema bicameral perfecto solo implican que esta segunda cámara debería ser excluida de la relación fiduciaria (como, por ejemplo, en el constitucionalismo inglés). No obstante, por las razones expuestas, en nuestra opinión esto no es deseable en una democracia. De hecho, si se previera una Cámara de los sabios, esta disposición debería conciliarse con el principio fundamental de la democracia: la igualdad de dignidad de los miembros de la comunidad política. Demostramos, en este sentido, que la unión de la elección y la edad mínima está ciertamente más en línea con el principio democrático, y desde luego con respecto a los nombramientos o sistemas políticos en cualquier caso orientados por criterios plutocráticos o tecnocráticos.

Si sobre esto llegamos a estar de acuerdo, si se armoniza la idea de una Cámara de los sabios con el principio básico de la democracia, se establece que también los miembros de la segunda Cámara deben ser elegidos por el pueblo (vinculando la sabiduría con la edad, con la experiencia adquirida, y limitando así el derecho de electorado activo y pasivo para una de las dos Cámaras), se deduce que no es posible, en el contexto de una forma parlamentaria de gobierno, excluir esta Cámara de los sabios de la relación fiduciaria. Precisamente por esta razón, el Senado italiano, compuesto casi en su totalidad por miembros elegidos directamente por el pueblo, no puede ser excluido razonablemente de la relación fiduciaria. Como dijimos, la identidad de las funciones deriva directamente de la composición de las dos cámaras.

Esto no significa que el bicameralismo italiano no pueda ser reformado, sino que si queremos cambiar las funciones del Senado, también debemos cambiar su composición, comenzando por el modo de formación (esto se aplica no solo al Senado italiano, sino a todos los sistemas en los que se discute la reforma del bicameralismo) ${ }^{22}$. La composición del Senado no puede que depender de las funciones que se le deben asignar (y viceversa).

22 Véase Castellà Andreu (2018b: 122), donde se lee, en relación con el Senado español, que «no cabe modificar las funciones del Senado sin cambiar su composición». 
Desde hace ya muchos años se debate en Italia la reforma del bicameralismo. Se trata de un tema que requeriría una reflexión específica y profunda que no se puede ofrecer aquí ${ }^{23}$. Es suficiente señalar que tiene sentido mantener un sistema bicameral solo si las atribuciones de ambas Cámaras, aunque diferentes, son significativas.

Parece que hay que excluir la idea de atribuir a las Cámaras reunidas la aprobación de las mociones de confianza y desconfianza. Durante el trabajo de la Asamblea Constituyente se hizo una propuesta similar, pero fue rechazada porque la asignación de estos poderes al Parlamento reunido, en lugar de a cada Cámara, podría haber creado serios inconvenientes. Un Gobierno podría haber obtenido la confianza de las Cámaras reunidas, pero no tener la mayoría que lo respalde en una de las dos ramas del Parlamento (Negri, 1959: 346). Si este argumento fue válido en el pasado, lo es aún más hoy. La forma parlamentaria de gobierno requiere una estrecha vinculación entre el Parlamento y el Gobierno. Especialmente en el mundo contemporáneo, la inestabilidad de los Ejecutivos - también debido al peso adquirido por las relaciones internacionales- es definitivamente insostenible. Este hecho no excluye que en una democracia se pueda prever un sistema bicameral en la que una de las dos Cámaras se concibe como de los expertos, sino que el Gobierno debe tener la confianza de cada Cámara por separado.

Manteniendo la composición del Senado sin cambios, sería problemático prever un mandato de duración diferente para los senadores o una ley electoral completamente distinta para el Senado. Ambas ideas se debatieron en la Asamblea Constituyente. La primera, de hecho, se aceptó: se estableció que el Senado se renovaría cada seis años, en lugar de cinco. También se aprobó que el Senado debería haber sido elegido con el sistema electoral mayoritario, en lugar de con el sistema proporcional.

Finalmente, nada de esto ocurrió. El Senado siempre se disolvió de antemano hasta 1963, cuando se modificó la Constitución para equiparar el mandato de los senadores con el de los diputados. De hecho, durante mucho tiempo, el sistema electoral fue el proporcional también para la formación del Senado. Tanto un mandato más largo para los Senadores como una ley electoral completamente diferente para el Senado parecen poder obstaculizar el correcto funcionamiento de la forma de gobierno.

23 No se cree que debido al resultado del referéndum celebrado en diciembre de 2016, en nombre de una forma mal entendida de realismo, debamos dejar de discutir sobre posibles reformas del bicameralismo: la doctrina debe estar atenta a la dinámica política, pero esto no debe significa subordinación de la doctrina respecto a los programas del partido. 
Al cambiar la composición del Senado, se podría perseguir la idea de poner los intereses de las autonomías regionales en el centro de la dinámica política a nivel nacional. Con este fin, si se estuviera de acuerdo sobre la necesidad de un órgano de enlace entre los diferentes niveles de gobierno del territorio, y especialmente entre el Estado y las regiones, el Bundesrat alemán podría realmente constituir un modelo. Sin embargo, en este caso sería necesario imaginar que las actividades de enlace se extiendan también al nivel supranacional, otorgando así al nuevo órgano competencias relevantes con referencia a la formación y aplicación del derecho de la Unión Europea ${ }^{24}$. Este discurso teórico debe entonces incluirse en la dimensión de la política práctica.

Hoy Italia, como dijimos al principio, tiene un sistema político que en gran medida se caracteriza por posiciones que son fuertemente críticas con respecto a la Constitución. En realidad, esto es bastante anormal. La Constitución, antes de ser un documento jurídico y político, es el pacto de la unidad nacional. También en el frente institucional debe expresar los valores en los que se reconoce toda la comunidad, independientemente de las divisiones de los partidos. Por supuesto, es completamente legítimo que las fuerzas políticas presenten propuestas para modificar la Constitución. Sin embargo, cuando casi todos los parlamentarios no se reconocen en la estructura institucional vigente en su conjunto (al menos visto por los programas de los partidos, por los discursos o propuestas de revisión presentadas), no estamos ante algo fisiológico. ¿Cuánto tiempo puede alargarse esta situación?

Solo algunos partidos están predispuestos a mantener la forma parlamentaria de gobierno ${ }^{25}$. A otros les gustaría modificarla (desde hace ya bastante, especialmente en el programa político de los partidos de centro-derecha, se encuentra la superación de la forma parlamentaria de gobierno) o revisar aún más profundamente el papel del Parlamento en nombre de una transición de la democracia representativa a la democracia directa.

En nuestra opinión, toda reforma del bicameralismo debe apuntar a mantener la forma parlamentaria de gobierno. De hecho, esta forma de gobierno es la más adecuada para una sociedad atravesada por profundas

24 El propósito de la reforma naufragada en diciembre de 2016 era también este (Rossi, 2016: 77). Sobre el entramado entre instituciones políticas europeas y nacionales puede verse Ibrido y Lupo (2018: 9 y ss.). Sobre el hecho de que los compromisos asumidos a nivel supranacional no deben de entenderse como un debilitamiento de la democracia parlamentar, véase Ruggeri (2020, 763 y ss.).

25 Sobre la estrecha vinculación entre conservación de la forma de gobierno parlamentaria y la propuesta de reforma del bicameralismo rechazada en 2016 véase (Bifulco, 2015: 69). 
divisiones políticas, económicas y sociales ${ }^{26}$. El cambio de la forma de gobierno, al menos en este momento histórico, podría poner en riesgo la supervivencia de la democracia en Italia. Queda por ver si las fuerzas políticas, en su actitud crítica hacia la Constitución, interpretan de la mejor manera los intereses emergentes en el contexto social. A raíz de los dos últimos referéndums constitucionales (ambos relacionados con nuevas redacciones ambiciosas y unilaterales de la segunda parte) parece ser que no.

\section{V. ¿̇DEL BICAMERALISMO ANÓMALO AL BICAMERALISMO OBSOLETO?}

Como se vio anteriormente, el bicameralismo paritario se consideró inútil e incluso perjudicial. Estas tesis se prestan a una explotación demagógica en el contexto público. Esto — está claro- no significa que solo por esta razón deban ser abandonadas. Sin embargo, el hecho que el riesgo de su distorsión populista (para usar un término muy de moda hoy) sea real no debe ocultarse.

Si tratamos de especificar las razones del riesgo en discusión, deberíamos indicarlas en la separación del vínculo que existe entre la institución y la justificación. En otras palabras, las críticas al bicameralismo igualitario dejan a la sombra el vínculo entre la composición y las funciones del Parlamento, tal como se desprende de la Constitución actual, y los valores constitucionales (forma de Estado). El hilo argumentativo que conduce de uno a otro (y viceversa) se rompe y la deriva demagógica está a la vuelta de la esquina.

Por un lado, el apelativo de inútil, e incluso perjudicial, antes referido solo al Senado (que según los rumores, luego desaparecidos, no hace mucho tiempo alguien habría propuesto convertirse en un $\operatorname{museo}^{27}$ ), termina siendo

26 Ya se señaló de manera sucinta en Minime considerazioni in vista del referendum costituzionale. Per una forma di governo parlamentare con bicameralismo asimmetrico (en Diritti regionali, 3/2016, pp. 533 y ss.).

27 El entonces presidente del Senado, Grasso, declaró a este respecto, cultivar «la remota esperanza» de que la política nunca «manifiesta la perspectiva de que incluso podamos dejar de recurrir a las instituciones para convertirlas en museos» (las declaraciones se leían en todos los principales periódicos del País. Ver también la refutación del entonces presidente del Consejo Renzi, a quien se le atribuyó la desafortunada expresión: "Riforma Senato, la maggioranza tiene. Grasso irritato: "No istituzioni come museo"”, artículo del equipo editorial, en repubblica.it, sección politica, 17 settembre 2015). 
aplicado al Parlamento, el "palazzo», con sus intrigas (para engańar al pueblo) (28 $^{28}$ y sus formalidades (insoportables, especialmente en un momento histórico en el que - esto es cierto- la esfera económica tiende a dominar la esfera política e institucional). El progreso tecnológico (y especialmente la red) parece permitir a cada ciudadano asumir directamente la tarea de tomar las decisiones políticas más importantes ${ }^{29}$. La red —en esa perspectiva- puede reemplazar a las instituciones parlamentarias, actuar como una plataforma a través de la cual los ciudadanos decidan ${ }^{30}$.

Por otro lado, este juicio de condena de la democracia representativa se justifica en nombre de los propios valores constitucionales, aquel principio al que nos hemos referido anteriormente: la igual dignidad de todos los miembros de la comunidad política ${ }^{31}$. La voluntad del pueblo debe imponerse a la

28 Que las instituciones siempre albergan intrigas es un ejemplo clásico de lo que Popper (2009: 580) llamaba teoría social de la conspiración: «Es la opinión según la cual todo lo que ocurre en la sociedad —incluidas las cosas que, por norma, la gente no ama, como la guerra, el desempleo, la pobreza, las carestías - es el resultado de un preciso propósito perseguido por algunos individuos o grupos potentes. Esta opinión es muy conocida, aunque se trata, si así se puede decir, indudablemente de una especie de superstición primitiva» (el filosofo no niega obviamente que hayan existido conspiraciones y que puedan seguir existiendo, pero objeta que no son tan frecuentes como los «complotistas» piensan ni tampoco siempre capaces de surtir los efectos esperados por los conspiradores).

29 A la tesis (en verdad criticable) según la cual en la democracia representativa los ciudadanos tienen un papel de simples «listeners», se opone que gracias al ordenador y a internet los ciudadanos podrán adquirir por fin un papel de protagonistas como «decision makers» (Grossman, 1995: 165).

30 Así, razonando, se desarrolla un verdadero misticismo de la red, que ya no se concibe como una mera herramienta de la que se puede hacer un uso bueno o malo. En este sentido, véase Frosini (2014: 62 y ss.), que a pesar de haber subrayado en más escritos el vínculo entre el desarrollo tecnológico y aumento de las libertades, afirma: «Certo, le tecnologie non producono solo libertà, per così dire: la tecnologia può essere al servizio dell'uomo buono o cattivo, del governante illuminato o del despota». En otras palabras, no se trata de mitificar el progreso tecnológico o de demonizarlo.

31 En realidad, se trata de un malentendido: en primer lugar porque se cree que la voluntad de las personas (es decir, la mayoría; a menudo incluso la mayoría de los miembros de un partido) se identifica con la verdad absoluta; en segundo lugar, porque, en consecuencia, se argumenta que los parlamentarios deberían estar obligados por ella, con lo cual se pierde el sentido mismo de la representación parlamentaria (y del pluralismo político). ¿De qué sirve, una vez que se ha identificado la voluntad del pueblo, un Parlamento compuesto por miembros constitucionalmente garantizados en su independencia? ¿Esta voluntad ya no puede ser expresada por un hombre solo? 
del Parlamento ${ }^{32}$; el número de los parlamentarios debe reducirse en nombre de la lucha contra el desperdicio y los privilegios; la prohibición del mandato imperativo debe cancelarse ${ }^{33}$; incluso el sorteo (al menos según algunas

32 Actualmente en Italia se está debatiendo sobre una propuesta de revisión constitucional (AS 1089) destinada, entre otras cosas, a modificar el art. 71 de la Constitución para establecer que «cuando un proyecto de ley está presentado por al menos quinientos mil votantes y las Cámaras no lo aprueban dentro de los dieciocho meses de su presentación, se celebra un referéndum para aprobarlo. Si las Cámaras lo aprueban con modificaciones que no son meramente formales, el referéndum se convoca a la propuesta presentada, salvo que los promotores no renuncien. La propuesta aprobada por las Cámaras está sujeta a promulgación si no se aprueba la que está sujeta a un referéndum» (lo que no parece respetuoso de la autonomía del Parlamento y parece corresponder exactamente a la oposición demagógica entre palacio y plaza).

El programa para las elecciones políticas de la Lega en 2018 dice (p. 20): «Democracia significa gobierno del pueblo. Su esencia consiste en la participación de las personas en el gobierno de la comunidad. Esta esencia está claramente esculpida por el artículo 1 de la Constitución italiana: "L'Italia è una Repubblica democratica, fondata sul lavoro. La sovranità appartiene al popolo, che la esercita nelle forme e nei limiti della Costituzione". Aparte de la expresión "fundada en el trabajo", resultado de la concesión a las solicitudes de los constituyentes socialistas y comunistas, queda clara la conexión entre democracia, soberanía popular y su ejercicio concreto. En este sentido, la democracia es uno de los principios supremos de la ley. Hoy, sin embargo, la soberanía del pueblo está cada vez más en riesgo por una serie de factores múltiples. Las propuestas políticas para la reforma de la Constitución incluyen lo siguiente: 1) El Parlamento debe hacer leyes, posiblemente pocas, simples y claras. No debe elegir al jefe del ejecutivo; 2) necesitamos un jefe del ejecutivo fuerte, elegido directamente por el pueblo, que no debe pasar por la confianza de las Cámaras y que puede nombrar y destituir ministros; 3) por lo tanto, es necesario prever la elección por parte de todos los ciudadanos italianos del presidente de la República, que combina los poderes actuales del presidente del Consejo y el presidente de la República, a excepción de la presidencia del CSM (Consejo Superior de la Magistratura); 4) la introducción del mandato con la reforma del art. 67 de la Constitución. No más cambios de partidos una vez elegidos. En la última legislatura hemos sido testigos de una vergonzosa trashumancia de representantes elegidos en una fila para pasar al opuesto. Los votantes ya no deben ser traicionados y deben tener la certeza de que sus representantes respetan el mandato que se les da. Cada persona elegida en el Parlamento debe perseguir el logro de los objetivos con los que se presentó a los votantes. El voto sobre personas, sobre disposiciones relativas a su territorio y sobre asuntos de conciencia queda excluido del vínculo; 5) luego sirve la eliminación del quórum para la validez de los referéndums populares, facilitando así ese ejercicio». En el "programa de asuntos constitucionales» del M5S (p. 4 y ss.) leemos que «la última legislatura ha registrado 
declaraciones hechas por algunas figuras políticas) debería recuperarse como criterio de decisión para reemplazar, al menos en algunos casos, las elecciones $^{34}$.

En un trabajo dedicado al bicameralismo italiano no es posible detenerse sobre todos estos temas. Sin embargo, hay dos preguntas en las que debemos insistir, aunque brevemente:

- ¿Es posible imaginar que una reforma del bicameralismo (y por lo tanto la superación del carácter, a juicio de muchos, anómalo del mismo) puede detener la deriva demagógica?

- ¿Pueden las nuevas tecnologías hacer posible fortalecer los instrumentos de democracia directa y participativa hasta el punto de hacer que el bicameralismo esté obsoleto?

A estas preguntas solo puede responderse tratando de identificar algunos principios generales.

alrededor de 500 [...] renegados nuevos partidos, con programas completamente diferentes a los aprobados inicialmente, nacieron directamente en el Parlamento, aprovechando la financiación pública sin cumplir con la voluntad de la gente. Para respetar la voluntad de los votantes, por lo tanto, es necesario detener el fenómeno del transformismo en el Parlamento, obligando a sus miembros a cumplir con el mandato recibido»; y de nuevo que «al eliminar el quórum del instrumento del referéndum es posible poner fin a la distorsión que condujo al fracaso de muchos referéndums celebrados en los últimos 20 años. De hecho, las partes han optado por abusar del instrumento del quórum estructural, sin el cual el referéndum no es válido, a veces invitando a los ciudadanos a no acudir a las urnas».

Como se argumentó en otras partes (sea consentido reenviar a La decisione a maggioranza nell'ordinamento costituzionale italiano, en dirittifondamentali.it, 1/2019, 17) el sorteo, como técnica de decisión, tiene orígenes fatalistas y es difícil de conciliar con la democracia, porque implica no igualdad, sino la invariabilidad de opiniones (y de personas). En la Constitución, el sorteo no encuentra mucho espacio: se menciona solo en la hipótesis muy singular (y patológica) de la acusación del jefe de Estado (también en combinación con la elección). Por otro lado, se argumentó que el sorteo podría usarse para identificar a algunos miembros del CSM o de las autoridades administrativas independientes o incluso para complementar la representación parlamentaria (lo que, se argumenta, sería muy útil para la aprobación de leyes electorales o relativas a la financiación de los partidos) y, por lo tanto, la composición de los órganos parlamentarios internos, in primis las comisiones de supervisión y las comisiones de investigación (véase, para todos, Scaccia, 2016: 4 y ss.). 
Si la reforma del bicameralismo refuerza el papel de las regiones (o, más ampliamente, de las autoridades locales) y, por lo tanto, se concibe en el sentido de revitalizar la participación, también puede servir como un antídoto para la deriva demagógica. La mejora de los organismos intermedios es fundamental para limitar el poder del Estado y para la participación efectiva de todos en la organización política, económica y social del país. Aún más serviría el propósito si al Senado se le asignaran competencias significativas - repetimos- con referencia a la dimensión europea.

Sin embargo, esta medida aisladamente no sería adecuada para detener la deriva demagógica, que sobre todo tiene su base en el aumento de la desigualdad económica y social. En nuestra opinión, por lo tanto, habría que concentrarse más en las reformas económicas y sociales que en las reformas constitucionales. $Y$ en cualquier caso, la reforma debe ser ampliamente compartida, más allá que solo por las fuerzas políticas mayoritarias.

Más complejo, y en muchos sentidos no lo suficientemente explorado, es el tema relacionado con el trade-off entre instrumentos de democracia directa/ participativa y segunda Cámara. Podríamos razonar de la siguiente manera. Si el propósito de un Senado que responda al modelo de Cámara de los sabios es asegurar que las opciones legislativas, especialmente en algunos casos (por ejemplo, las leyes en materia constitucional), se estudien más cuidadosamente, ¿este objetivo no podría lograrse mejor, en su total respeto por la autonomía del Parlamento, a través de la participación de las personas en los procedimientos correspondientes?

Se podría imaginar la abolición del Senado y el refuerzo de los instrumentos de democracia directa (por ejemplo, la introducción del referéndum propositivo) y participativa (por ejemplo, la introducción del referéndum consultivo). Incluso se podría prever que para las leyes en materia constitucional el proceso de formación de la ley «se acerque» al procedimiento más complejo previsto para las leyes constitucionales, contemplando la posibilidad de solicitar un referéndum si no se alcanza un quórum especial predeterminado.

Muchas otras podrían ser las reformas viables. Está claro que desde el punto de vista político las opiniones pueden ser las más variadas, pero esto no es lo que nos interesa aquí. En cambio, lo que cuenta es comprender si el modelo de la Cámara de los sabios, aunque sea compatible y esté bien armonizada con el principio democrático, no sea objetivamente superado o destinado a ser superado también por el desarrollo de las tecnologías ${ }^{35}$, lo que promete

35 Véase D’Atena (2019: 588) que advierte sobre una preocupante «aspiración a la desintermediación» que «encuentra una expresión radical en la idea que, en un futuro 
que sea más sencillo el uso de instrumentos de democracia directa y participativa (y menos costoso) en el marco de una redefinición (en hipótesis) equilibrada de las relaciones entre el Parlamento y el pueblo.

En otras palabras, ¿el bicameralismo italiano está obsoleto (o está destinado a convertirse obsoleto)? La respuesta parece ser negativa. De hecho, el desarrollo tecnológico y la posible introducción de nuevos instrumentos de democracia directa y participativa no implican la obsolescencia del Senado que, incluso en su composición actual, conserva plenamente su justificación — si damos por sentado el consenso sobre la necesidad de preservar las instituciones de democracia representativa, no vemos por qué debe considerarse injustificado un Parlamento en el que una de las dos Cámaras está compuesta por hombres con más experiencia- En términos de producción legislativa también debe recordarse que la Constitución actual ya permite que el pueblo desempeñe un papel decisivo a través del referéndum abrogativo. Piénsese al respecto en los referéndums sobre aborto, divorcio, ley electoral. Sin embargo, esto ciertamente no indujo a los constituyentes a considerar superflua la previsión de una segunda Cámara. La estructura del Parlamento puede modificarse y los instrumentos de democracia directa y participativa pueden fortalecerse con la condición de que se salvaguarde la autonomía del Parlamento. La involución plebiscitaria debe, por otro lado, evitarse: cualquier revisión de la Constitución sería ilegítima si, alterando el equilibrio entre el Parlamento y el pueblo, la favoreciera privando al primero (aunque solo para algunos aspectos) de autonomía.

\section{CONCLUSIONES}

El Senado italiano originalmente basa su justificación —al igual que otras Cámaras Altas - en la forma de Estado aristocrático.

Con la transición a la democracia, conserva su naturaleza como Cámara de los sabios, en una forma compatible con el principio de igualdad de dignidad de todos los miembros de la comunidad política. Este aspecto relacionado con la composición del Senado no debe ser (mitificado ni) olvidado.

Hemos sostenido que el Senado mantuvo su naturaleza de Cámara de los sabios poniendo en valor lo que dispone el art. 58 de la Constitución italiana. Hemos considerado entonces no compartir las tres principales explicaciones alternativas al bicameralismo italiano: la primera, según la

no muy lejos, pueda incluso prescindirse del Parlamento, ya que las decisiones podrían ser tomadas, en tiempo real, directamente por los ciudadanos conectados a la red». 
cual las dos Cámaras serían necesarias para garantizar una mejor calidad de la legislación, nos parece difícil de demonstrar y rechazada por la comparación con ordenamientos monocamerales; la segunda, por la cual el Senado sería una cámara inconclusa y destinada a transformarse en la rama representativa de las regiones, parece determinar una superposición entre interpretación del derecho viviente e hipótesis de reforma; la tercera, por la cual el bicameralismo italiano sería fruto de las contingencias políticas y no susceptible de explicarse de otra manera, podría aceptarse solo a falta de explicaciones alternativas.

Según la opinión de quien escribe, el art. 58 consiente entender el Senado como Cámara de los sabios, como además en la Italia llamada liberal. La elección de los senadores (con la sola excepción del grupo restringido de los senadores vitalicios) señala una discontinuidad neta con el régimen prerrepublicano y enlaza con la caracterización democrática del Estado.

Si la propuesta de ley de revisión constitucional relativa a la reducción del número de parlamentarios fuera aprobada, esto no modificaría mucho las consideraciones desarrolladas en este trabajo. La proporción entre número de diputados y número de senadores quedaría tal cual, como también quedarían iguales esos elementos de diferenciación sobre los cuales intentamos llamar la atención. Podemos solo añadir al respecto que la disminución del número de lo representantes no determinaría un ahorro significativo bajo el punto de vista de las cuentas públicas. Se duda que pueda servir para forzar la representación parlamentaria y es posible que, aunque independientemente de otras modificaciones, determine al revés un mayor alejamiento entre los representantes y los ciudadanos. El tema merece un análisis por separado y profundo que en este contexto no es posible ofrecer. Sea suficiente observar que la reducción del número de los parlamentarios es solo aparentemente una modificación pequeña y razonable y, considerada junto con otras propuestas en discusión, parece más que nada dirigida a debilitar la institución parlamentaria y recibir una fácil aprobación.

A lo largo de este trabajo quisimos además señalar que el hecho de que las dos Cámaras tengan las mismas funciones, puede considerarse anómalo solo en relación con la forma parlamentaria de gobierno. Sin embargo, es necesario tener en cuenta que la identidad de las funciones deriva directamente de la composición (y particularmente del modo de formación) de las dos Cámaras, a su vez correlacionadas con la posibilidad de optar por un modelo específico de segunda Cámara y con la forma de Estado.

Es posible, por supuesto, cambiar la composición del Parlamento, respetando los principios fundamentales (jincluida, por supuesto, la autonomía del propio Parlamento!), pero no es razonable argumentar que el Senado, en su configuración actual, esté objetivamente obsoleto o que, debido a un posible 
desarrollo de los instrumentos de democracia directa y participativa, su presencia en el sistema institucional debe considerarse superflua.

\section{Bibliografía}

Ackerman, B. (2000). The New Separation of Powers. Harvard Law Review, 113 (3), 633-729. Disponible en: https://doi.org/10.2307/1342286.

Bagehot, W. (1995) [1867]. La Costituzione inglese. Trad. it. S. Pastorino. Bologna: Il Mulino. Bifulco, R. (2015). Osservazioni sulla riforma del bicameralismo (d.d.l. cost. A.C. 2613-A). Le Regioni, 43 (1), 69-82.

Bin, R. y Ruggiu, I. (2006). La rappresentanza territoriale in Italia. Una proposta di riforma del sistema delle conferenze, passando per il definitivo abbandono del modello Camera delle Regioni. Istituzioni del federalismo: Rivista di Studi Giuridici e Politici, 27 (6), 903-954.

Brennan, J. (2018). Contro la democrazia. Roma: Luiss University Press.

Bull, M. J. y Newell, J. L. (2009). Still the Anomalous Democracy? Politics and Institutions in Italy. Government and Opposition, 44 (1), 42-67. Disponible en: https://doi. org/10.1111/j.1477-7053.2008.01275.x.

Caravale, G. (2000). Il bicameralismo britannico nel duemila. Quaderni costituzionali, 20 (3), 545-566.

Castellà Andreu, J. M. (2018a). El Senado español ante su reforma. En J. M. Castellà Andreu, S. Pajno, G, Rivosecchi y G. Verde (eds.). Autonomie territoriali, riforma del bicameralismo e raccordi intergovernativi. Italia e Spagna a confronto. Napoli: Editoriale Scientifica.

- (2018b). Estado autonómico e integración constitucional. Madrid: Marcial Pons.

Ceccanti, S. (2015). Constitutional change: an explanation. Journal of Modern Italian Studies, 20 (2), 202-212. Disponible en: https://doi.org/10.1080/1354571X.2015.997492.

Cecchetti, M. (2018). Il bicameralismo in Italia: un nodo (ancora) in attesa di soluzione. En J. M. Castellà Andreu, S. Pajno, G, Rivosecchi y G. Verde (eds.). Autonomie territoriali, riforma del bicameralismo e raccordi intergovernativi. Italia e Spagna a confronto. Napoli: Editoriale Scientifica.

Cheli, E. (1987). Bicameralismo. Digesto delle discipline pubblicistiche, 2, 318-325.

Chessa, O. (2013). Il bicameralismo dei Saggi. Le Regioni, 41 (4), 665-678.

D’Andrea, L. (2018). Democrazia e potere economico: la "forma» del primato costituzionale. Rivista AIC, 3, 996-1018.

D’Atena, A. (2019). Democrazia illiberale e democrazia diretta nell'era digitale. Rivista AIC, 2, 583-596.

De Fiores, C. (2007). Prospettive di riforma del bicameralismo in Italia. Politica del Diritto, 38 (4), 527-568.

Di Ciolo, V. (1989). Senato (diritto vigente). Enciclopedia del Diritto, 41, 1164-1199. Milano: Giuffrè.

Doherty, B. (1996). Seanad Ėireann. Constitution Review Group Report 4 (The National Parliament). Dublin: Government of Ireland. 
Elliott, M. y Thomas, R. (2017). [2011]. Public Law. Oxford: Oxford University Press. Disponible en: https://doi.org/10.1093/he/9780198765899.001.0001.

Ellul, J. (2014) [1991]. Storia delle istituzioni. L'età moderna e contemporanea dal XVI al XIX secolo. Trad. it. G. Ancarani. Milano: Mursia.

Fernandez Segado, F. (1982). El bicameralismo y la naturaleza del Senado. Revista Española de Derecho Constitucional, 6, 61-113.

Ferrara, G. (1984). Art. 55-63: Le camere. En G. Branca y A. Pizzorusso (eds.). Commentario della Costituzione. Le Camere, tomo I. Bologna: Zanichelli; Roma: Soc. ed. del Foro italiano.

Frosini, T. E. (2014). Internet come ordinamento giuridico. En M. Nisticò y P. Passaglia (eds.). Internet e Costituzione: atti del convegno di Pisa del 21 e 22 novembre 2013. Torino: Giappichelli.

Gélard, P. (2006). Report on Second Chambers in Europe: Parliamentary complexity or democratic necessity? European Commission for Democracy Through Law (Venice Commission). Disponible en: https://bit.ly/33RAZ0X.

Grossman, L. K. (1995). The Electronic Republic. Reshaping Democracy in the Information Age. New York: Penguin.

Hayek, F. A. von (2011). La società libera. Trad. it. M. Bianchi di Lavagna Malagodi, L. Infantino, N. Iannello. Soveria Mannelli: Rubbettino.

Ibrido, R. (2017). Per un regolamento comune del procedimento legislativo. En F. Bassanini, A. Manzella (eds.). Due Camere, un Parlamento: per far funzionare il bicameralismo. Firenze: Passigli.

— y Lupo, N. (2018). «Forma di governo» e «indirizzo politico»: la loro discussa applicabilità all'Unione europea. En R. Ibrido y N. Lupo (eds.). Dinamiche della forma di governo tra Unione europea e Stati membri. Bologna: Il Mulino.

Lijphart, A. (1984). Democracies: Patterns of Majoritarian and Consensus Government in Twenty-one Countries. New Haven: Yale University Press. Disponible en: https://doi. org/10.2307/j.ctt1ww3w2t.

Lippolis, V. (2012). Il bicameralismo e la singolarità del caso italiano. Rassegna Parlamentare, 54 (1), 29-48.

Lupo, N. (2018). Funzioni, organizzazione e procedimenti parlamentari: quali spazi per una riforma (coordinata) dei regolamenti parlamentari? Federalismi, 1-31. Disponible en: federalismi.it

(2019). Il «mezzo voto» ai cittadini più giovani: un’anomalia da superare quanto prima. Osservatorio AIC, 6, 71-81.

Manzella, A. (1977). Il parlamento. Bologna: Il Mulino.

Melis, G. (1990). Fascismo (ordinamento costituzionale). Dig. disc. pubbl., VI. Torino: Utet.

Mortati, C. (1946). Il potere legislativo: unicameralismo o bicameralismo? En C. Mortati. Studi sul potere costituente e sulla riforma costituzionale dello Stato. Raccolta di scritti, vol. I. Milano: Giuffrè.

Negri, G. (1959). Bicameralismo. En Enciclopedia di Diritto, Vol. V. Milano: Giuffrè.

Pace, A. (2016). La riforma Renzi-Boschi: le ragioni del no. Rivista AIC, 2, 1-23.

Pajno, S. (2018). La cooperazione intergovernativa dopo il fallimento della riforma costituzionale. En J. M. Castellà Andreu, S. Pajno, G, Rivosecchi y G. Verde (eds.). Autonomie 
territoriali, riforma del bicameralismo e raccordi intergovernativi. Italia e Spagna a confronto. Napoli: Editoriale Scientifica.

Paladin, L. (1990). Bicameralismo. Enciclopedia di Diritto, Vol. III. Roma: Treccani.

Pérez Serrano, N. (1976). Tratado de Derecho Politico. Madrid: Civitas.

Pezzini, B. (1990). Il Bundesrat della Germania federale. Il modello tedesco e la riforma del bicameralismo nello Stato a base regionale. Milano: Giuffrè.

Popper, K. R. (2009). [1969]. Congetture e confutazioni. Lo sviluppo della conoscenza scientifica. Trad. it. G. Pancaldi. Bologna: Il Mulino.

Predieri, A. (1963). Pianificazione e Costituzione. Milano: Giuffrè.

Przeworski, A. (2010). Democracy and the Limits of Self-Government. New York: Cambridge University Press. Disponible en: https://doi.org/10.1017/CBO9780511778490.

Reynoso, D. (2009). Las variedades del bicameralismo en América Latina. Miríada, 2 (4), 9-50.

Rossi, E. (2016). Una Costituzione migliore? Contenuti e limiti della riforma costituzionale. Pisa: Pisa University Press.

Ruggeri, A. (2006). Revisioni costituzionali e sviluppi della forma di governo. Forum di Quaderni costituzionali.

- (2015). Una riforma che non dà ristoro a Regioni assetate di autonomia. Le Regioni, 43 (1), 243-256.

— (2020). Integrazione sovranazionale e democrazia parlamentare. Diritti fondamentali, 1 , 738-760.

Salerno, G.M. (1998). Il Senato tra riforma del bicameralismo e rappresentanza degli enti territoriali. Le Regioni, 26 (1), 9-46.

Scaccia, G. (2016). Democrazia a sorte: problemi e opportunità. Nomos, 2.

Scalia, A. (2018). [1997]. A Matter of Interpretation. Federal Courts and the Law. Princeton: Princeton University Press. Disponible en: https://doi.org/10.1515/9781400882953.

Schmitt, P. (2014). Comparative overview of consultative practices within the second chambers of EU national legislatures. European Union, Committee of the Regions. Disponible en: https://bit.ly/2FWdjjX.

Seijas Villadangos, M. E. (2016). [2014] La historia del constitucionalismo español y la Constitución de 1978. En M. A. Castellá Andreu (ed.). Derecho constitucional básico. Barcelona: Huygens.

Wheare, K. C. (1963). Legislatures. Londres: Oxford University Press. 